\title{
Oficina de Atividade Natalina: uma Proposta Terapêutica a Familiares
}

\author{
Ferreira, Maria Flávia Frajácomo; Pinto, Bruna Teixeira; Lanza, Ana Luiza; \\ Bérgamo, Daniela Carvalho \\ Hospital Estadual Américo Brasiliense — mflavia_ferreira@yahoo.com.br
}

\begin{abstract}
INTRODUÇÃO Entende-se o adoecimento enquanto um momento de crise, resultando em modificações da estrutura familiar anteriormente estabelecida. (Lustosa, 2007). em um contexto de cuidados paliativos a intervenção ao familiar reforça sua importância ao considerar a vivência de terminalidade do ente querido. Os familiares necessitam de um espaço que the proporcione segurança e estabilidade, se caracterizando enquanto um momento para acolhimento e expressão dos próprios conteúdos. (Mendes, Lustosa e Andrade, 2009). Culturalmente, existem eventos e datas comemorativas que remetem ao encontro familiar e à aproximação de seus membros. ao considerar a ruptura existente a partir do adoecimento e hospitalização e assim, a impossibilidade de vivenciar na integralidade as datas comemorativas significativas, como o Natal, percebe-se a importância de uma forma de resgatar e aproximar esta vivência, ainda que em um ambiente hospitalar. OBJETIVOS Promover um espaço grupal destinado a familiares de usuários em cuidados paliativos em um hospital geral para realização de uma atividade facilitadora de expressão de conteúdos vinculados a uma data comemorativa com representações em torno do vínculo familiar. MÉTODOS o grupo foi realizado por uma terapeuta ocupacional e uma psicóloga. a preparação para o grupo: - Confecção de modelos de cartões natalinos; - Organização do material; - Organização da sala com disposição das cadeiras em roda, uso da música e a exposição dos materiais. a realização do grupo: - Convite verbal aos familiares presentes no momento do grupo; Apresentação dos membros e da proposta da atividade, a qual resultará na troca de cartões natalinos entre os participantes da seguinte forma: os cartões confeccionados no 1.0 encontro serão entregues pelos coordenadores aos participantes do 2.0 encontro e assim sucessivamente. 01.0 grupo receberá os cartões confeccionados pelos participantes do último encontro via correio; - Os cartões deverão conter uma mensagem de livre escolha do participante; - Oferta de auxílio dos profissionais quando necessário. RESULTADOS Foram realizados 2 encontros e um total de 4 participantes. no decorrer da atividade, emergiram conteúdos em torno da vivência de adoecimento, hospitalização e terminalidade. a atividade favoreceu a aproximação entre os participantes. CONCLUSÕES a oferta de um espaço acolhedor favoreceu a identificação e construção de recursos favoráveis para enfrentamento da situação vivenciada a partir da elaboração da mensagem a ser destinada a um outro familiar em situação semelhante contendo palavras de incentivo. Houve a oferta de um ambiente saudável em um momento de cuidado dentro de um contexto de adoecimento. a atividade, considerando a data comemorativa, possibilitou contribuir para uma visão integral do usuário, considerando seus familiares e sua cultura, como também, favoreceu a identificação de demandas para intervenções específicas das áreas presentes.
\end{abstract}

Ferreira, Maria Flávia Frajácomo; Pinto, Bruna Teixeira; Lanza, Ana Luiza; Bérgamo, Daniela Carvalho. Oficina de Atividade Natalina: uma Proposta Terapêutica a Familiares. In: Anais do Congresso Internacional de Humanidades \& Humanização em Saúde [= Blucher Medical Proceedings, num.2, vol.1]. São Paulo: Editora Blucher, 2014. ISSN 2357-7282

DOI 10.5151/medpro-cihhs-10507 